\title{
Episode 4
}

\section{Grace gets Some Help}

Curiouser and curiouser!

\section{From: Dan Rossi}

Sent: $\quad 16$ September 2009 11:03

To: $\quad$ Grace Inge

Subject: Re: WAY out of my depth

Grace,

I've found someone to help you. He is brilliant with numbers and can explain everything to you. But you are going to have to go centre-stage on this one - he's just not the type you can put in front of a bank or investors; he's more of a backroom boy. He does numbers, not people.

It will be a good opportunity for you really to get to grips with the company's financesit's about time you learned their importance!

I'll make the introduction by separate email and leave you to sort out fees etc. with him. I don't believe he'll be that expensive.

Keep in touch, Grace. These are interesting times.

Dan

From: Grace Inge

Sent: $\quad 16$ September 2009 15:01

To: Dan Rossi

Subject: Re: WAY out of my depth

Dan,

Where do you find these people? Anyway, he and I have spoken and agreed terms. He has already started asking lots of questions, which is good, because if I understand the question I feel I have a better chance of understanding the answer. If only balance sheets had been an optional module at design school (except I probably wouldn't have taken it)!

Dan, you're a star and I owe you big time. Dinner's on me next time.

Grace Inge

CEO

MissInge Fashions 